\title{
Lessons for China and other Developing Economies from the Crisis in US Auditing
}

\author{
Michael Alles. Rutgers University. USA. \\ alles@business.rutgers.edu
}

\author{
Alexander Kogan. Rutgers University. USA. \\ kogan@andromeda.rutgers.edu
}

Miklos A. Vasarhelyi. Rutgers University. USA. miklosv@andromeda.rutgers.edu

\begin{abstract}
The continuing series of business scandals, from Enron to WorldCom have severely undermined the credibility of auditors and audited financial statements in the US. With developing economies such as China looking to emulate western models of corporate governance, what lessons should they draw from these apparent failures in auditing? There is a danger that those opposed to modernization of accounting and auditing will use these scandals as an excuse to delay the adoption of new standards and methods. Indeed, the Enron/Andersen scandal was apparently one reason that Chinese authorities watered down proposals to require firms seeking new Class-A shares to hire a foreign auditor to supplement their local auditor. In this paper we discuss a more productive lesson that developing countries seeking to bring their accounting infrastructure up to Western levels can draw from the recent US experience, using China as a case study. China is the most important of all developing economies, and its impending entry into the WTO makes reform there particularly urgent. The path that China takes is also likely to serve as a role model for much of the rest of the developing world, especially in South East Asia. We argue that developing countries have the opportunity to "leapfrog" existing auditing techniques in the West that have proven to have serious shortcomings, and instead, go straight to the cutting edge methodologies of continuous assurance and tertiary logging. Continuous assurance is a type of auditing which, by making use of the "electronization" of the firm, produces audit results simultaneously with, or a short period of time after, the occurrence of relevant events. In comparison with the traditional financial statements audit, continuous assurance is distinguished by being timelier, more comprehensive, more accurate and more supportive of the management process. These capabilities are especially valuable for Chinese firms who face an environment with weaker legal, regulatory and management controls than in the West. However, the tenuous nature of
\end{abstract}


the auditing infrastructure in China makes it essential that it also adopts tertiary logging as a way of "guarding the guards". We discuss how logging the audit in a continuous assurance setting will increase the deterrence capability of peer review, as well as serving as a source of institutional memory in the case of mandated auditor rotation, the separation of auditing from consulting and the unique Chinese proposal for dual auditing.

Key words: China, continuous auditing, Sarbannes-Oxley, Enron

\section{INTRODUCTION}

In this paper we examine the lessons that developing economies can draw from the current crisis in US auditing, using China as a case study. China is an important area for research in its own right, being an emerging economic superpower, and reform of its accounting and auditing infrastructure is particularly urgent with its impending entry into the World Trade Organization. The increased competition and openness that WTO membership necessitates argues for the acceleration of ongoing initiatives that are designed to achieve convergence of accounting, auditing and governance practices between China and the West. But there is a danger that these accounting driven scandals -in Australia and Europe as well as in the US- that culminated in the collapse of the once revered firm of Arthur Andersen, will result in emerging economies abandoning the aim of emulating western business practices ${ }^{1}$. Given the current inadequacies with auditing and accounting in the PRC we feel that this would be a shortsighted mistake. Rather, China should take advantage of the lessons the US has learned at such cost from the Enron debacle to instead "leapfrog" ahead to a state of the art audit system utilizing the new methodologies of continuous assurance (CA) and tertiary logging ${ }^{2}$. Making sure that reform in China stays on track is especially important, not just because of the size of its economy, but because it is likely to be as important a role model for other developing economies as Japan was in its heyday.

\footnotetext{
$1 \quad$ "Backsliding on corporate governance issues is a long-established habit in many Asian countries. Results of a survey by the Association of Certified Chartered Accountants have given little hope for progress, except in China where CFOs have made the strongest connection between finance and best practice." CFO Asia, December 2002.

2 Encouragingly, Chinese Premier Zhu Rongji and Finance Minister Xiang Huaicheng forcefully reemphasized the commitment of the Chinese government towards achieving greater harmony in accounting and auditing standards, strengthening independence, monitoring and supervision of accountants and improved corporate governance, at the $16^{\text {th }}$ World Congress of Accountants in Hong Kong in January 2003. As the Premier memorably put it to auditors: "Make no false accounts!" See http://www.acca.co.uk/publications/ $\underline{\text { studentaccountant } / 828028}$.
} 
Continuous assurance systems, which build upon the enterprise resource planning (ERP) architecture of a firm, enable faster, more accurate and more sophisticated auditing. However, CA systems are perhaps even more susceptible than conventional auditing methods to collusive fraud between management and compliant auditors. The fact that there has been several such cases documented in the PRC leads to the conclusion that CA, especially in China, needs to be supplemented with a system of tertiary logging that will answer the question of "who guards the guards". We propose to make use of the capabilities of CA systems to construct a "log file" of the audit, which will enable an audit of the audit, thereby deterring collusion between managers and auditors. The log file will also help maintain the integrity of the audit in the event of auditor change or rotation, and in particular, will ensure consistency in the unique circumstances in the PRC of dual auditing. We conclude by also commenting on the implications for the PRC of the forcible separation of auditing from consulting, as has been mandated in the US by the recently passed Sarbanes-Oxley Act.

\section{AUDITING AND ACCOUNTING IN THE PRC}

Given its ancient culture and long history, it is not surprising that China was one of the first nations in the world to develop rudimentary methods of accounting and auditing. A form of auditing apparently emerged as early as the Western Zhou Dynasty, 3,000 years ago ${ }^{3}$. A royal audit court was set up in the Song Dynasty in 992 A.D. and from then on, every dynasty established specific institutions or offices in charge of monitoring state revenues and expenditures. However, in the first 30 years after the founding of the People's Republic of China in 1949, accounting and auditing focused on the control of a centrally planned economy. It is only with the shift towards a market economy over the last 25 years that accounting and audit standards and practices have come to resemble those in the West. The Ministry of Finance (MOF) issued the Basic Accounting Standard in 1992, while the Chinese Institute of Certified Public Accountants (CICPA) started issuing audit standards in $1994^{4}$.

\footnotetext{
See the discussion of the history of accounting at http://www.cnao.gov.cn/ and at http://www.americanaccounting-professionals.com/history/historical-accounting.htm.

$4 \quad$ Narayan and Reid (2000) provide a comprehensive survey of financial management and governance issues in the PRC.
} 
Despite impressive gains in a relatively short period of time, with an ongoing process to bring local accounting standards in line with International Accounting Standards, accounting, corporate governance and financial management remains challenging areas in China today. The nearly 300,000 State Owned Enterprises (SOE) remain far behind private sector and joint-venture firms in the quality of their financial and accounting management ${ }^{5}$. For example, in December 1999, a random audit of 100 SOEs found that 81 of them had reported a total of Y3.8 billion (US\$ 459 million) of false assets, while 89 SOEs reported false profits totaling Y2.7 billion (US\$ 326 million). Worse, previous audits of these 100 SOEs by 82 public accounting firms resulted in 62 of them receiving clean opinions ${ }^{6}$. Even in Hong Kong, which has long followed UK and IAS standards, spectacular business failures, such as that of Peregrine Investments and CA Pacific Securities has brought the quality of accounting and financial management into question.? The situation in Mainland China is compounded by the lack of adequately trained personnel and shortcomings in the legal and regulatory framework ${ }^{8}$. Chinese authorities have had to rely on highly publicized crackdowns to catch wrongdoers after the event rather than relying on a corporate governance infrastructure to deter securities fraud in the first place ${ }^{9}$. But this is a second best solution at best, and there are clear concerns that the continued development of the Chinese economy will suffer in the absence of transparency and trust.

In response to these problems bodies such as the MOF, CICA, the Bank of China, the China National Audit Office (CNAO) and the Chinese Securities Regulatory Commission (CSRC) have undertaken various initiatives to update and strengthen accounting, auditing and financial regulations and the level of training and integrity of finance professionals. One of the most striking of such initiatives was the announcement by the CSRC in December 2001 that all firms seeking new A-share listings (domestic listings, as opposed to B-shares which are

\footnotetext{
5 See Webb (2002).

$6 \quad$ Hua Sheng Bao, $12^{\text {th }}$ December 1999.

7 Cheung (1999). The rather hostile reaction of the Hong Kong accounting profession to the Sarbanes/ Oxley Act is documented in the Hong Kong Accountant, September 2002.

8 See European Chamber of Commerce in China (2001), American Chamber of Commerce in the PRC (2002).

9 For example, Chinese securities regulators are in the second year of an ongoing crackdown into share price manipulation and irregular corporate-asset restructuring. (Wall Street Journal, China Targets Price Manipulation, Thursday August 15 ${ }^{\text {th }}$, 2002, p. C14).
} 
stocks denominated in Hong Kong and United States dollars and which were originally reserved for foreign investors) had to have their books audited not just by a local audit firm, but by an international firm as well ${ }^{10}$. The aim of this unique dual or "buddy" auditing system was clearly to raise the standards of local auditors, both by providing them with a role model, as well as deterring them from developing too cozy a relationship with their clients. Unfortunately, the assumption that simply being foreign implies that the auditor is more competent and has higher integrity was undermined by the scandals that were taking place at the same time in the US. The "Arthur Andersen" argument was evidently used by local auditing firms to persuade the CSRC to water down its proposal. In February it announced that the regulation only applies to firms seeking to raise more than US\$ 36 million in an initial public offering, and that the second auditor only has to be one that is officially recognized by the CSRC and the Ministry of Finance as being familiar with international accounting standards. No further definition of what a firm must do to be so recognized was included in the regulation.

This episode indicates that the fallout from the current series of business scandals in the US and the extent to which they have undermined accounting and auditing has not been restricted to that country. It is important to understand the impact of these matters on China's ongoing program to modernize its auditing and accounting infrastructure. Despite the continuing crisis in US auditing and business, few observers -especially those in the PRC- will disagree that the underlying problem is far worse in China itself ${ }^{11}$. But that also is China's great opportunity, if it so chooses to seize it. Since accounting in China is in a state of development and flux, it is actually easier to bring about fundamental change there than in a country such as the US, where a well-established accounting infrastructure with its vested interests, makes it harder to achieve consensus on the need for change- as evidenced, for example, by the struggle to enact the Sarbanes-Oxley Act with its relatively minor amendments to US securities regulation.

\footnotetext{
10 This provision had previously been applied to A-share firms in the banking, securities and insurance sectors in February 2001 (People"s Daily, February 14 $4^{\text {th }}, 2001$ ).

11 For example, see "Sacking of Auditors in China A Worrying Trend", South China Morning Post, July 17, 2002: "The Chinese Institute of Certified Public Accountants ("CICPA») has expressed concerns over several cases of "malignant sacking” of auditors who failed to issue an opinion over the fairness and completeness of the financial statements and their notes to the accounts."
} 
The continuous audit methodology that we discuss in this paper is the focus of intense interest by both accounting academics and practitioners, and has been adopted, as least in part, by leading firms around the world ${ }^{12}$. A prerequisite for its use is the implementation of a comprehensive ERP system, and that is very costly for a well-established firm to do because of the need to replace its many legacy systems. A firm just setting up its IT system for the first time, on the other hand, would adopt an ERP system as a matter of course. It is that logic which makes ERP systems, and so the CA that ERP enables, well suited for the leading Chinese firms that are consciously evolving towards modern management practices. Of course the cost and complexity of ERP technology makes CA unsuitable at present for the mass of small Chinese firms. But there is a deliberate policy in the PRC of targeting a small number of large firms to be the leading edge for the rest of the economy and it is these firms that are ideally suited to put into practice the lessons learnt from the crisis in the United States.

We now turn to a discussion of what these lessons are and the possible role of continuous assurance in overcoming these problems.

\section{CONTINUOUS ASSURANCE IN THE WAKE OF THE ENRON SCANDAL}

In Congressional testimony on February 4th, 2002, Harvey Pitt, Chairman of the US Securities and Exchange Commission (SEC), put forward a set of proposals for reforming accounting and auditing in response to the unprecedented crisis of confidence that has gripped financial markets in the wake of scandals at Enron, Global Crossing, WorldCom, Xerox, Adelphia and others ${ }^{13}$. The essence of his argument was the use of more timely and comprehensive information to increase market confidence in financial statements, auditors and the actions of managers, and this focuses attention on the role that continuous assurance will play in the

\footnotetext{
12 For example, see the special issue on continuous assurance in Auditing: A Journal of Practice and Theory, March 2002. AICPA (1997) and CICA/AICPA (1999) helped formulate the profession"s expectations of how CA will evolve auditing methodology. See also Vasarhelyi (2002). In October 2002, centers for continuous auditing research were simultaneously established in the United State and in the European Union. The US center, based at Texas A\&M University, has the US Comptroller General as the chair of its advisory board, demonstrating the importance attached to this new audit methodology.
}

13 http://www.sec.gov/news/testimony/020402tshlp.htm. 
future of auditing in the US. Indeed, in follow-up testimony before Congress on February 14th, 2002, American Institute of Certified Public Accountants (AICPA) Chair James Castellano explicitly stated that a greater emphasis on continuous assurance would be one of the principal responses of the accounting profession to the shortcomings highlighted by the Enron/Andersen failure:

"The transition to new reporting and auditing models is going to demand not only new audit approaches but personnel of the highest caliber. With this in mind, the profession has been working actively in the following areas: Continuous Auditing or continuous assurance involves reporting on short time frames and can pertain to either reporting on the effectiveness of a system producing data or more frequent reporting on the data itself. An AICPA task force has concluded that the enabling technologies, if not the tools, required to provide continuous assurance services, are, for the most part, currently available. Their actual implementation will evolve with progressive adoption of the concept and the emergence of appropriate specialized software tools" ${ }^{14}$.

Continuous assurance is only one of the consequences on financial statement preparation, monitoring and reporting of the increasing "electronization" of business (Slivotzky and Morrison, 2000; Vasarhelyi and Greenstein, 2002). ERP systems, such as SAPTM, enable an entire corporation to be managed "by wire". With the ubiquity of bar coding, scanning, automatic transaction recording, and the low cost of data storage and retrieval, companies no longer need be constrained to rely on conventional double-entry bookkeeping and a chart of accounts to aggregate and record information. Smart warehouses utilizing radio frequency smart chip-based labels, as well as Internet-based implementations of electronic data interchange (EDI) and newer business-to-business protocols such as ebXML and BizTalk enable low cost business information capture at the source. XBRL enables financial information to be accessed frequently and flexibly to create customized and easily communicated reports and disclosures. As a result, all but the smallest firms have or soon will have the capability to record and report transactions in real time.

14 http://energycommerce.house.gov/107/hearings/02142002Hearing490/Castellano804print.htm. 
Much of the attention CA has gained recently stems from the belief that the way in which the mandated annual audit takes place will have to change to reflect and to take advantage of the new real-time enterprise systems that companies are installing. Thus auditors, as a way of reducing the cost and increasing the effectiveness of the annual financial statements audit, will increasingly install monitoring software that will overlay the company's own IT systems, and these systems can then be "piggybacked" upon to offer the capability for continuous assurance. Alles, Kogan and Vasarhelyi (2002) examined the conceptual differences between "continuous" and standard auditing and pointed out that the likely constraint on the development of CA was not the availability of technology, but uncertainty over whether the demand existed for enhanced assurance products. The current furor over inadequate control and supervision at firms suggests that this demand is now more likely to arise and CA may finally be propelled into the auditing mainstream in the United States. By contrast, in China there has long been consensus on the need for a more rigorous audit environment and so presumably there is likely to be less resistance to the adoption of CA methodologies, at least by those firms that have the capacity to implement ERP and compete on the world stage.

Alles et al. (2002), however, examined the economic viability of CA in the pre-Enron environment where CA was seen simply as a supplement to standard periodic auditing. In the light of the expressed views of the SEC and the AICPA, the effectiveness of continuous assurance in preventing reoccurrences of the kind of corporate failures characterized by management fraud combined with compliant, or indeed collusive auditing that have so shaken market confidence needs to be examined rather than presumed.

\section{CONTINUOUS ASSURANCE AND MANAGEMENT CONTROL}

The most benign interpretation of the kinds of corporate failure that the US has witnessed recently is that they are nothing more than examples of poor management, exacerbated by inadequate flows of information between managers and the board of directors (the "few rotten apples" theory put forward by President Bush). This interpretation has the least set of broader implications, since such 
problem can be alleviated in the electronized firm, with ERP systems allowing senior managers to dig into the details of transactions about which they have concerns and CA systems providing real-time assurance and a more sophisticated set of analytics.

CA extends the analytical methods of traditional audit by examining continuous flows of data, with models of system behavior used to establish expectations for data content. Monitoring the content of data flows focuses on examining both exceptional transactions and exceptional outcomes of expected transactions. CA software will continuously monitor company transactions, comparing their generic characteristics to observed/expected benchmarks, thus identifying anomalous situations. When significant discrepancies occur, alarms are triggered and are routed to the appropriate stakeholders. For example, alarms with exceptional materiality can be routed to the SEC in the US, or the MOF or CSRC in China. An example of innovative banking regulation using $\mathrm{CA}$ is the provision of real-time audit facilities by the Italian bank, BIPOP to the Italian Central Bank ${ }^{15}$.

Figure 1 illustrates the use of alarms in a CA environment, describing the "alarm object", its triggering mechanisms and contingencies. Associated with the concept of alarm is the idea of "acknowledgement"-alarms that have to be acknowledged by controllers, internal and external auditors and senior management. An acknowledgement through a special form of electronic signature can be attached to a transaction tag (via XML) and selectively become part of the management log, thereby establishing clear lines of responsibility.

To consider the role that $\mathrm{CA}$ might play in deterring corporate failure, consider that if CA had been in place at Enron then it would have been much harder for CEO Jeff Skilling to claim, as he did in Congressional testimony on February 7th, 2002, that: "On the day I left, on Aug. 14, I believed the company was in strong financial condition. I wasn't there when it came unstuck... This was a very large corporation, it would be impossible to know everything going on." CA could also have been designed to provide timely reports to the board of directors on the consequences for Enron of the various "special purpose entities" (SPE) that

15 Voarino and Vasarhelyi (2002). 


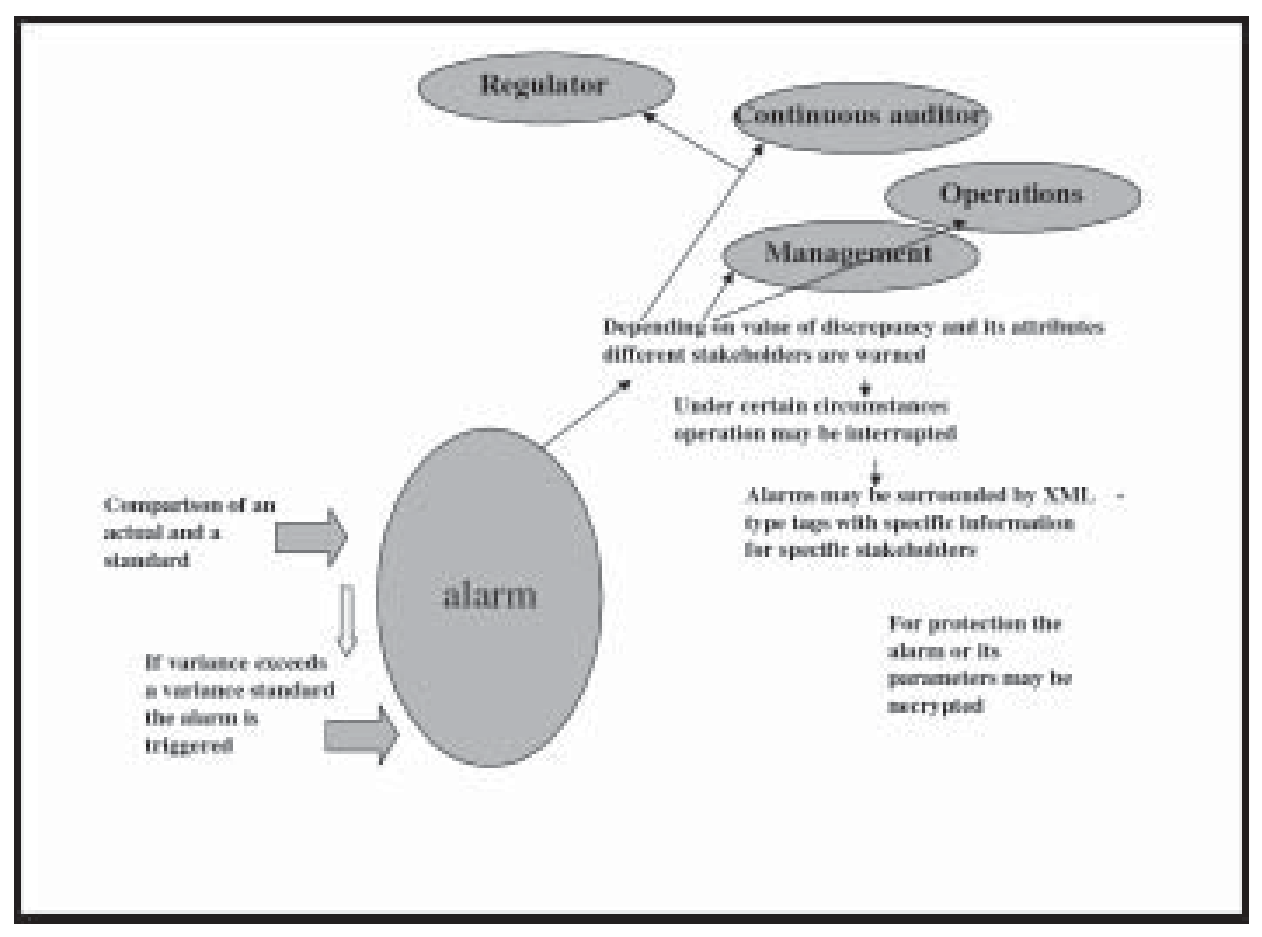

Figure 1. The Alarm Object

ultimately sank the company, because of their unrecognized downside. Indeed, before SPEs were established, managers armed with sophisticated financial software might have been able to carry out "what if" analyses under such scenarios as a declining stock price and disclose their results concerning the changes effected on the corporate risk profile due to the SPE.

CA might also have played a role in deterring lower level managers from gaming the system. To take but one example, energy traders at Enron deliberately understated the volatility of their portfolios by manipulating trades around the day each month on which the volatility was measured ${ }^{16}$. CA is not needed to resolve a glaring error like announcing beforehand when monitoring will take place. But it can be used to automate routine controls and so remove the human element that is subject to making such an error, either because of incompetence, overconfidence, or collusion. CA methodology would reduce the cost of taking

16 “Enron: How Good an Energy Trader?” Business Week, February 11 $1^{\text {th }}, 2002$, page 42. 
such measurements on a more random, or even on a continuous real time basis, consequently making such manipulations harder to perpetrate. It could also ensure that actions did not take place prior to necessary authorizations were obtained from senior management, as apparently took place at Enron ${ }^{17}$. Essentially, the deployment of CA greatly enhances the capabilities of a firm's internal control system, allowing for real time monitoring and tracking of significant operational and financial decisions.

Managers in China have no illusions about the need for tighter and more modern management control systems, with even the most internationally minded firms having suffered from embarrassing and costly frauds in recent years, such as those in the Bank of China and the China Everbright Bank ${ }^{18}$. Given its own series of Enron-like scandals, the greater adoption of CA can only help in raising standards of management control and oversight in Chinese firms.

\section{CA IN A FRAUD ENVIRONMENT}

The hypothesis behind corporate failure that has gained the most currency in the American public's mind, however, is not that it is due to lack of controls alone, but rather, it is the result of deliberate fraud by managers, aided and abetted by compliant auditors. For example, the treatment of US $\$ 7.1$ billion of expenses at WorldCom as assets is the most basic form of accounting fraud, and its auditor (Arthur Andersen, of course...) was harshly questioned in Congress as to the purpose of an audit if it could not capture such egregious earnings management. In other cases, such as with Global Crossing, Adelphia and Tyco, there are indications that managers conducted transactions designed largely for their own enrichments rather than because of any interest of the company.

A situation in which company officers are carrying out deliberate fraud, let alone one in which the auditor is looking the other way, presents the greatest

\footnotetext{
17 “Web of Details Did Enron In as Warnings Went Unheeded”, N.Y. Times, February 10 ${ }^{\text {th }}$, 2002, page 1.

18 The Bank of China lost some US\$ 483 million at its Kaiping branch in Guangdong through money laundering and questionable loans (New York Times, March 16 $6^{\text {th }}, 2002$ ). The scandal at China Everbright, China's sixth largest bank, was especially embarrassing because it used to be a showcase bank for China, with the Asian Development Bank having bought a large stake in it in the 1990s. Ironically those funds were intended for the purchase of the latest computers, financial software and training (New York Times, August 16 ${ }^{\text {th }}, 2002$ ).
} 
challenge to auditing in general, and to CA in particular. Unlike in a case of poorly designed controls or a lack of clear communication, collusive fraud raises the possibility of deliberate manipulation of the CA system itself. The ability of CA to benchmark in real time data content against expected values and continuous relationship among processes, which is the strongest new capability it brings to control, can be made redundant if it is the parties being monitored who determine the transactions which trigger alarms.

For example, in the case of round-tripping by energy traders such as Enron and Dynergy, if auditors and managers program the CA system to consider matching transactions as routine then all such transactions would slip under the wire of the CA system. The ability to set such defaults makes the CA system less effective than a manual audit system, where there is always the possibility that conscientious new auditors might raise questions about transactions that they consider unusual-and indeed, this is precisely what happened at WorldCom and Adelphia ${ }^{19}$. The value of a fresh set of eyes is also the logic behind the proposed dual auditing structure in the PRC.

It had long been assumed in the US that the presence of an auditor was largely sufficient as a check on such actions of management, with bankers, analysts and credit agencies playing a backup oversight role. But the recent sequence of spectacular failures was brought about by a systematic failure on the part of almost all the parties involved in corporate governance. In particular, auditors, who are paid directly by the auditee and who gain a big chunk of their revenue from consulting rather than auditing are considered particularly susceptible to pulling their punches with important clients. China has seen its own share of scandals with compliant auditors, with, for example, Shenzhen Zhongtianqin, one of the larger of its local audit firms recently having its license revoked by the CSRC for failing to detect Y745 million (US\$ 90 million) in fabricated profits at its client, the Guangxia (Yinchuan) Industry Holdings Co. ${ }^{20}$.

\footnotetext{
19 Ironically these companies switched auditors as part of a self-righteous rush by its clients to dump Arthur Andersen.

20 http://sg.biz.yahoo.com/020227/46/2k0mp.html
} 
In light of these structural problems, the question of "who guards the guards?" can no longer be assumed away. The only form of tertiary review that currently exists in the US today is SEC reviews of financial statements and peer review of auditors. However, in practice, both these practices have proved to be inadequate to the task. The SEC rarely conducts reviews of firms, partly by inclination, but mainly because of a severe lack of staff accountants and the funds to hire them ${ }^{21}$. The lack of properly trained and adequately compensated staff at regulatory bodies is an even more pressing concern in China than it is in the US. CICPA has undertaken a series of initiatives over the last decade to consolidate the number of accounting firms in China and to raise their level of competence and training. But there is as yet no ongoing process of effective supervisory review. Indeed, during the rectification campaign of 1997-1990, self-inspection was the main process utilized (Narayan and Reid, 2000).

As for the US system of peer review, the fact that Andersen successfully passed a peer review during the Enron debacle has hardly inspired confidence in that procedure $^{22}$. To use an analogy, the current peer review system is the equivalent of the ISO 9000 process, which certifies that a firm has put in place control systems to ensure Total Quality Control. But being ISO 9000 certified is not meant to guarantee that the firm actually achieves industry-leading quality output, only that it has the minimal controls without which quality production is simply not feasible.

Since the current peer review system consists of one major audit firm examining all the activities undertaken by another over a three-year period, it is virtually impossible to analyze even a single large audit down to the data level. Fully examining the audit of every client of every auditor is also prohibitively costly and wasteful, even if it were technically practicable. But a superficial examination becomes a rubber stamp, with little deterrence value. In particular, colluding managers and auditors can easily sidestep such a review.

21 “Will SEC”'s Needs Be Met? Not by Bush”, New York Times, February 8, 2002, page C1.

22 http://peerreview.aicpaservices.org/firmfile/firmdetail.asp. 
Not surprisingly, since its inception there has been no qualified or adverse peer-review opinions issued by one major audit firm on another (though several small audit firms have been cited), showing to the public a flawless profession in stark contrast with the increasing number of recent audit failures. Thus, the peer review is essentially a test of controls rather than a form of substantive testing, and while such tests have their place, they are ultimately based on a presumption of good faith by the auditee. In the current environment such a maintained assumption by one Big-4 auditor on another strikes the public as too self-serving.

One way to move in a cost effective way towards having the peer review consist of a mixture of controls and substantive testing of key transactions of major audit clients is to make better use of CA systems. They allow for a largely automated data scrutiny and analysis across a large number of audit engagements undertaken over several years, making both cross-sectional and time series comparisons. The electronization that underlies $\mathrm{CA}$ also allows it to be as easily accessed by outside parties as by the firm and its auditor. As such, it can serve as a window into the firm for the peer reviewer. Moreover, the use of sophisticated alarms and monitors allows for third parties to focus in on the most significant transactions without being buried by a mass of routine detail. This would allow the peer reviewer to actually examine a subset of actual underlying audit records, or monitor the changes on the auditor's electronic working papers rather than simply verifying systems. But even so, CA alone cannot solve the problems with peer review, because of the volume of material to be reviewed and the difficulty any third-party has in reconstructing what really took place in a complex and extended audit.

Even more so than in the US, tertiary monitoring -"guarding the guards"- is a particularly urgent necessity in China, with its proliferation of very small audit firms and poorly trained auditors ${ }^{23}$. The proposed "buddy system" for the audit of large firms, with a local auditor paired with a foreign auditor -effectively one of the Big-4 firms- is a form of tertiary review, but its base assumption is that merely being foreign is sufficient guarantee of integrity. The problems that Ernst \& Young

23 We define primary monitoring as the control of firm activities by the firm's own internal control architecture, while secondary monitoring is provided by the oversight exercised by the external auditor. There has been very little attention paid to the concept of tertiary monitoring-the control of the activities of the external auditor. 
have had with the audit of Gazprom in Russia indicates that even having a Big-4 firm as an auditor does not necessarily improve corporate governance in foreign locations with weak infrastructure. The CSRC proposal now appears as an almost anachronistic example of the deference once shown to the major accounting firms. The counterarguments made by Chinese auditors indicate that reputation alone is no longer considered to be an acceptable substitute for an effective system of tertiary review.

\section{GUARDING THE GUARDS: LOG FILES IN CONTINUOUS ASSURANCE}

While CA has the potential to enhance the technical capabilities of peer review, its Achilles' heel is the possibility that the very managers and auditors that it is designed to monitor will manipulate its settings. It is clearly infeasible for the peer reviewer to impose its own CA system across all the clients and audit engagements of the auditor that it is reviewing. This means that it is the CA system already put in place by the auditor, which is itself heavily dependent on the IT systems of the auditee, that will underlie the peer review. This poses a severe threat to the integrity of the peer review and the confidence in its findings.

To increase the effectiveness -both real and perceived- of audit quality control procedures, and to further improve the CA methodology Alles, Kogan and Vasarhelyi (2003a) put forward the concept of the "black box audit log file" (BB $\mathbf{L o g}$ ). Their proposal discourages manipulations of the CA system by the auditor or the auditee by making such manipulation more visible, through the creation of a confidential "log" of audit procedures (and other economic events) in the CA system. This CA logging proposal can be viewed as an extension of the existing practice of documenting audit activities in manual or automated work papers and preserving them for a set time period. However, the log proposal goes far beyond the existing practice by utilizing CA to systematically implement in auditing such standard control principles as adequate records maintenance, separation of duties and proper authorization of audit activities. In particular, the log file will capture the critical decisions that directly affect the effectiveness, and hence credibility, of the audit, such as the benchmarks for the automated analytic procedures. This log file will be secure and read-only, and be searchable by a peer reviewer, thus allowing the review to be conducted at a level of detail that is currently unattainable. 
Figure 2 describes a summary view of the proposed BB Log, which includes three complementary log streams, a log of key transactions and events, a log of selective control actions and processes and a log of audit processes drawn from actions in automated working papers. These logs, together, allow for the re-creation of the economic circumstances at the auditee, at a certain moment in time, and the evaluation of the auditor's actions.

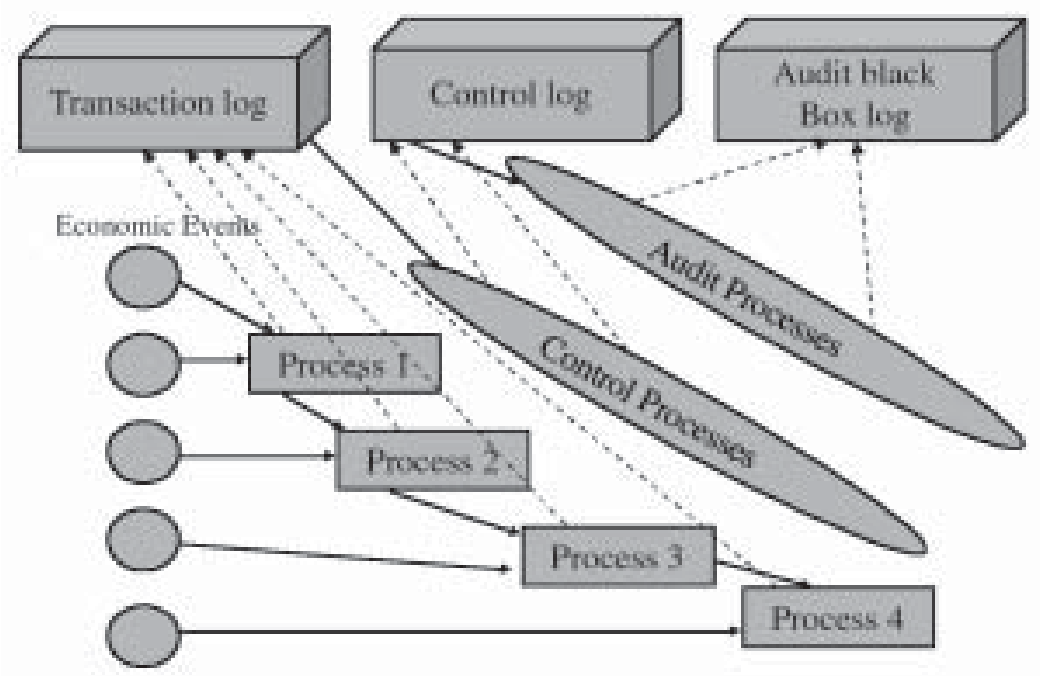

Figure 2: Levels of Logging

The point of the $\log$ system is to create a permanent record of the most important audit procedures with an "audit trail" of its own. This log system should keep track of the defaults built into the CA system and clearly establish lines of responsibility. It can serve as a gatekeeper between managers and significant policy decisions on an audit, requiring auditors and auditees to state what they are doing in a medium that will permanently record their actions and allow for third party review of them. The intent is to deter fraud and collusion by making managers and auditors aware that objective records exist of what they knew and did, and when they knew and did it.

The key to making this system work is making the log itself comprehensive, private and secure in its contents and inviolate to change, i.e., making sure that it is impossible to "shred" the audit log file. A variety of technologies and procedures 
have to be involved here. Access has to be granted to view the log at some point, but essentially it would be "read-only" and encrypted. The master records may be kept under the supervision of a third party such as the peer reviewer, the SEC, a commercial firm such as those that today guard offsite corporate computer backups, or the new Public Companies Accounting Oversight Board set up by the SarbanesOxley Act. In the PRC, the MOF can delegate this responsibility to a body such as the CSRC or the CNAO. The organization of the log has to be carefully though through in order to prevent it from simply becoming a digital data dump in which it will be impossible to find the critical information needed to police the auditor. Sophisticated and largely automated search and database organizational features must be built in so that auditors will face a high likelihood that reviewers of the $\log$ file will indeed examine their actions more thoroughly than is the case now, in the absence of logging.

While the log file is primarily designed for use by the assuror of the quality of the audit work, be that a peer reviewer of the audit firm or another body chosen by regulators, the log file's existence would also provide additional assurance for bankers, analysts, credit agencies, institutional investors and others concerned about the quality and integrity of the audited financial information provided by the auditee. Different gradations of confidentiality can be built in to control levels of access. In the event of corporate failure, governmental agencies would have access to all log file records.

While unique in its application and intent, the BB log file is somewhat analogous both to the "black box" carried by commercial airliners and to the security camera in a retail store. A plane's black box cannot fly the plane or prevent crashes, but it can help quickly identify what went wrong; similarly, while the log file cannot replicate the audit in every detail, it will help unravel the critical decisions that led to corporate and audit failure-and, unlike with an airlines black box, the knowledge that there will be ex-post transparency will have an ex-ante deterrent effect. The security camera also has a deterrent effect -as indicated by the fact that it is possible to purchase fake, non-functional cameras- but it does not preclude all attempts at theft. By the same token a log file will not end all instances of audit fraud or incompetence, but by making the actions of auditors more susceptible to review, it will make them want to do their jobs better and so increase the audit's credibility with its consumers. 
The BB log proposal could be implemented at several levels of complexity or intrusiveness. The extremes would be pure archival nature use (data is gathered and dropped in an external trusted bucket) to dynamic interactive use where extensive analytics are performed in the data streams, alarms generated, summarization and synchronization performed, statutory reports generated, and notes to archive examiners introduced. At the first level the BB log acts as a pure archival receptacle, as in a black box flight recorder on an aircraft. Forensic accountants and regulators may eventually have access to it. The BB $\log$ at its higher level is a proactive tool that extends CA scrutiny, acts as an intrusive deterrent of management and auditor malfeasance, and may feed third party continuous supervisory algorithms ${ }^{24}$.

The log file can also serve as an additional means of communication by the auditor, supplementing the audit opinion. In recent Congressional testimony, US senators demonstrated great surprise at the fact that auditors only have a very blunt pubic signal -qualify/don't qualify- to cover what is surely a continuous range of possible audit opinions. The problem is that the market may interpret in the worst possible light any kind of qualification, however marginal or immaterial. As one senator put it, the only option to an auditor who has concerns with the firm is to acquiesce, or else to use the "nuclear bomb" of qualification, risking destroying a client over what may be a relatively minor accounting disagreement.

While allowing for more nuances in the audit opinion is a useful goal, a more immediate solution is to allow the auditor to semi-publicly express any reservations in the log file. This information would allow the reader of the log file to readily pinpoint areas of the audit history that warrant further investigation or to identify instances of lack of zeal, competence or collusion by the auditor. If the auditor has not logged a comment, then there would be a presumption that there was complete agreement with the client, and the auditor and auditee would not be able to blame each other. Of course, auditors may then start to log everything as a way

\footnotetext{
24 See Alles et al. (2003a) for more details on the BB Log File proposal. They emphasize that much discussion and debate is needed on what should be recorded into a log file, who should have access to it and under what circumstances. These decisions will determine whether the log file becomes simply an extension of current audit working papers, or a fundamentally new form of corporate oversight. A key issue is drawing the line between the firm's internal operational and control logs and the external log of the audit itself (see Figure 2).
} 
of covering themselves, but even so, the gray areas would be easier to identify as a result.

The log file can also serve as a vehicle for communicating any other information that potentially raises questions about the perception of integrity of the audit, but which do not rise to the level of a mandated disclosure. Thus while there are already mechanisms for revealing such issues as insider trading and consulting fees paid to audit firms, the log file can deal with such other potentially troublesome concerns as the tenure of audit partners and the revolving door between auditors and the firm.

The scale and scope of information that will be logged in a log file is likely to be considerable. It is quite clear that without a CA system deployed it is difficult to create an audit log file as described above. On the other hand, if a CA system is available, then the requirement of maintaining the audit log file should not be too burdensome, partly because much of this data has already been collected by the firm's ERP system for its own internal decision making purposes, and partly because it is not difficult to make a CA system log its formal activities. All that is happening is that the information is being stored in a secure and confidential way so that a third-party reviewer can quickly find out and assess what managers and auditors are doing. More fundamentally though, the log file is making use of the unique technological capabilities of CA to develop new audit tools that were not feasible before, as opposed to seeing CA as just an incremental advance of existing audit methods. It is the difference in perspective between reengineering and automation, and as business has found out, rethinking processes rather than rethinking technologies is the only way to access the productivity improvements that new technologies offer.

The most significant barrier to logging is not technical, but institutional. There has to be incentives provided for auditors to $\log$ in the first place, and appropriate penalties for not doing so. In the US, having a defense in the event of civil litigation and the desire to reduce the costs of liability insurance is likely to be the main inducements for audit firms and audit committees to encourage the use of logging and the specification of what should be logged. Generally Accepted Auditing Standards can also be amended to specify a set of minimal logging events, which are then added to on a case-by-case basis by the auditor and the firm. 
Developing the institutional framework within which logging operates may be actually easier to bring about outside the United States, in countries such as the PRC, where there is a greater acceptance of government regulation. In particular, given the evolving state of accounting in China and concerns with the legal environment, foreign audit firms in particular may welcome logging as a safeguard for themselves. That will also encourage their greater involvement in the Chinese market. Bodies such as the MOF, the CSRC and CICPA are likely to take the lead in mandating the need for logging and the content of the BB log file, as well enforcing its implementation.

Ultimately whether logging becomes part of the auditing mainstream is a function of supply and demand, as Alles et al. (2002) pointed out in regard to CA itself. If there are less costly substitutes available to ensure audit integrity, or no lack of confidence with existing audit methods, then there is less demand for innovative practices. But when the reputation of audit firms is brought into question and investors lose trust in the numbers reported to them, then new practices are needed for auditing to retain its credibility, and hence, its value. This analysis suggests that emerging economies such as China, with their still developing corporate governance systems, should be in the vanguard of innovation in audit methods. The ability to thereby leapfrog to state of the art accounting, without having to repeat the mistakes experienced by more advanced economies is a bonus source of competitive advantage that should not be ignored.

\section{LOGGING TO PRESERVE INSTITUTIONAL MEMORY IN AUDIT ENGAGEMENTS}

In the wake of the Enron/Andersen scandal, a great deal of interest has been expressed lately in the idea of term limits for audit engagements, with mandated rotations of auditor after three to five years ${ }^{25}$. While the Sarbanes-Oxley Act only mandated the rotation of the audit partners (every five years) the issue remains open in the US. We discuss this issue here to further illustrate the potential and power of the BB log file proposal. It is a particularly pertinent issue in the current context, given that one of the first places to mandate rotation is Singapore, with 
regard to certain financial institutions. This is an example that Chinese authorities will no doubt follow closely, and contrast it with their proposed approach of dual auditing. We shall also discuss here the role of logging in the dual auditing setting.

The aim of mandatory rotation is to deter too cozy a relationship developing between auditors and firm management, as well as to deter collusion between them because of the knowledge that a new auditor will scrutinize any arrangements between them. The audit profession has long opposed mandatory rotation, arguing that a long engagement allows auditors to gain experience and knowledge about the firm, as well as lowering overall costs for auditors, firms and society in general (see e.g., Bell et al. 1997). It has also been argued that given the high startup cost of a new audit engagement, the new auditor will be especially reluctant to take on a new audit client to avoid jeopardizing the future rents necessary to recover the high sunk cost of the new engagement. Empirical research in auditing seems to support this point of view (Geiger and Raghunandan, 2002).

Whatever the merits and prospects of this proposal are, it is useful to discuss the implications of a greater reliance on CA if term limited audits come into practice. Alles et al. (2002) point out that CA will require a high setup cost as customized software is piggybacked onto the firm's ERP system, since it would be impractical for the auditor not to take advantage of the firm's own IT architecture. They go on to discuss the critical question of who will own the CA overlay and the effect that different ownership and payment arrangements will have on auditor independence, and the relative bargaining power of the auditor and the auditee. These questions are particularly relevant if the auditor has to be rotated every few years.

The reliance of the new auditor on a CA system that it had no role in creating is problematic. The ability of management to affect system settings and set defaults means that the new auditor will have to first audit the CA system, a task made difficult by its lack of first hand knowledge of how the system has evolved. Obviously the auditor also cannot rely overly on those who do have that prior knowledge of the CA system-management and the previous auditoræbe cause that would undermine the logic of mandatory auditor changes in the first place. This difficulty with the transition between auditors can be greatly ameliorated however, if there is a BB log system in place. The logs will provide an objective 
explanation to the new auditor of how the CA system has reached its current state and the interactions between management and the previous auditor that have given rise to it. Furthermore, audit logs can be built as knowledge structures that explain what assurance procedures are automatically performed and how they interact.

The rationale for auditor rotation is a lack of trust that the auditor won't collude with management given the chance to develop a long-term relationship. Since that is also the basis of the fraud setting which prompted the proposal for a log file, it is only to be expected that a log system would be invaluable in a term limited audit environment. It will serve as a source of impartial institutional and audit process memory that can survive auditor changes and also allow the new auditor to more quickly ascertain what kinds of changes the old team had made to the CA system and what defaults they had agreed upon.

In the dual auditing setting, a log file can serve as a mechanism for one auditor to comment on the other and to list areas of consensus and disagreement. It will also facilitate changes in one or both auditors, enabling the new auditor, be it the local or the foreign one, to quickly ascertain what the current state of the audit is. Otherwise the new auditor will be in an immediate disadvantage relative to the auditor that remains. Achieving dynamic stability under a dual audit system is an issue that the CSRC perhaps needs to think through further. There is a danger that a buddy system might actually entrench the power of the auditor who holds on to the client the longest, so undermining the intent of the regulation. A log file system will help redress that balance.

\section{DIVESTING CONSULTING FROM AUDITING}

Another contentious issue that has arisen in the US in the wake of the Enron/ Andersen scandal is whether to mandate the separation of auditing from consulting (Alles et al. 2003b). The Sarbanes-Oxley Act goes a long way towards restricting the scope of the services that auditors can provide in the United States, and this has only accelerated the tendency of the major audit firms to divest themselves of their audit arms ${ }^{26}$. The question that China faces is whether to go down this same

\footnotetext{
26 By contrast, the United Kingdom authorities chose to impose no new restrictions on consulting activities by auditors, opting for greater disclosure instead. That is at least an alternative model for China to consider. See “Britain Introduces New Accounting Rules" New York Times, January 29 2003.
} 
road, given that arguably it has both bigger independence concerns, as well as a greater need by its firms for the management advisory services that auditors can provide.

The independence problems associated with audit firms doing consulting for audit clients -exemplified by the US\$27 million Andersen earned from consulting for Enron in 2001, as opposed to US\$ 25 million in audit fees- is clear enough. But those advocating complete separation have to acknowledge that such a policy also imposes costs on the firm, the auditor and society as a whole. In the case of China, integrity has been hard to police even in the case of audits alone, without adding consulting to the mix. But at the same time, when dealing with firms whose own management control systems are still weak and developing, the line between consulting and auditing is harder to draw, and imposing a separation between them is particularly problematic. Moreover, Chinese firms hiring foreign audit firms may have higher expectations of what they hope to get out of that relationship in terms of knowledge transfer.

To understand why any complete separation between auditing and consulting inevitably leads to unnecessary societal costs, one has to consider the effects that a audit should normally have on the internal management control system. If the management control system were absolutely perfect, then the audit process would not discover any abnormalities, the auditors would certify the financial statements on the basis of this negative outcome of the audit process, and the statutory audit would not affect the management control system in any way. Of course, real systems are never perfect, and the audit process always identifies certain abnormal events that have to be dealt with. These abnormal events are identified by the audit tests and procedures conducted as part of the audit process. The probabilistic properties of the stream of abnormal events captured by the audit process can provide important information about the root causes of these abnormalities. Kogan, Sudit and Vasarhelyi (1999, page 94, emphasis in the original) formulate an important hypothesis about these probabilistic properties:

"Since the auditing system is by its own nature a parallel system, it should not be relied on for routine control functions, i.e., for detecting systematic problems. Therefore, the auditing system's alarms should be truly random, i.e., these alarms should be a Poisson-like process... If the stream of audit alarms is not completely 
random, then the COA system is probably being relied on for some systematic signals. These signals should be normally provided by the internal management control system."

While Kogan et al. (1999) raise this point in the limited context of continuous auditing, their argument is much broader, speaking to assurance as a whole, and it has particular significance for the debate over the boundary between auditing and consulting. Unless the audit process results are truly random, then the audit process is generating new knowledge, and the auditors are responsible for communicating this new knowledge to management and/or board of directors. Indeed, auditors in the US are required to issue a letter to management commenting on the company's internal controls and any needed improvements to them. This particular outcome of the audit process is not that dissimilar from the outcome of a consulting engagement focused, say, on competitive benchmarking, since it provides new information, not a confirmation of existing knowledge. The fact is that, since no management control system is perfect, there must be new knowledge gained from conducting an audit. That is particularly the case for firms, such as those in China, who have not had much prior experience of audits as sophisticated and comprehensive as those provided by the Big-4, and whose own management control systems are relatively undeveloped.

If the abnormalities detected by the audit process do not appear to be random, then their root cause is very likely to be a systematic problem in the internal management control system. The capability of the audit process to detect such non-random abnormalities is usually due to the development by the auditors of special procedures or sets of test focused on potential systematic problems. For example, in the case of the audit of accounts payable, the auditor might have developed special procedures to identify duplicate payments. Then, if this audit sub-process identifies some duplicate payments, the auditor will have to address this issue with the management and make sure that the identified duplicate payments are recovered. However, such a recovery, while correcting the problem in this particular audit, will stop short from addressing the underlying systematic problem with the internal management control system.

Since an audit is an on-going event (except for the last year in a term limited contract), if there is a non-random signal one year because of a systematic problem, 
then it is likely to reoccur the following year too, unless the systematic cause is dealt with. If the management does not fix the problem, then the audit process will continue dealing with and correcting for a non-random stream of abnormalities generated by the systematic problem. In this case, the audit process will in effect become a part of the managerial control system, since it will have to correct issues caused by systematic problems. This is not an acceptable outcome, since it will result in the audit itself institutionalizing inefficiency and error, which is contrary both to the requirements of professional standards, the spirit of an audit and to what investors think an audit is supposed to do.

In our example, the elimination of duplicate payments as a systematic source of audit events can be achieved by a transition of the system developed by the auditor into the internal managerial control system. Such transition will be usually viewed as consulting, especially because it is a fair expectation on the auditor's part to be additionally compensated for this system. Therefore, such transition becomes impossible if a strict separation of audit from consulting is put in place. Then, the remaining option is for the client to develop a similar system itself, or to hire a management consultant other than the external auditor to carry out this development. Such development will eliminate the systematic problem and improve the internal control system, but it will be clearly inefficient from the societal point of view, since it will very likely duplicate what the auditor has already done. That is particularly the case in emerging economies, such as China, where resources are limited and need to be used as effectively as possible. In the case of China, it is surely the case that Big-4 audits in particular will generate a great deal of information that will be of use to Chinese audit clients and which is simply too valuable to discard. The high startup costs of initiating audits of Chinese firms may also require that foreign audit firms be allowed to extend consulting services as an additional inducement to enter the market in the first place.

The dynamic process of migrating certain tests and procedures developed by the auditor into operations will inevitably result in certain parts of the managerial control system being essentially developed by the auditor. While this improves the managerial system, it will also create another problem with auditor's independence in an ongoing engagement since the auditor will essentially have to audit a part a his own work. The longer the term of a properly conducted audit engagement, the more serious this problem will become. 
One way to deal with this issue is to impose term limits on the auditor by mandating auditor rotation, but as discussed in the prior section, that policy has costs and benefits of its own. Auditor rotation can be facilitated by a wide deployment of continuous auditing and the adoption of the BB log file enabled by CA. The log file can also record what information generated by the audit is transferred to the firm's management control system, so enabling the line between consulting and auditing to be more easily identified. More importantly, logging can also serve as a substitute mechanism for strengthening the integrity of an audit if auditor rotation and the separation of auditing and consulting are ruled out as too costly a means of ensuring independence.

\section{CONCLUSION}

The testimony by the SEC and the AICPA to the US Congress presents a sanguine view of the ability of continuous assurance to prevent the kinds of systematic problems with auditing brought to the surface by the Enron/Andersen scandal. While CA unquestionably represents a dramatic increase in the power of auditing, it is important that its strengths are not oversold and its weakness underestimated. Where there is fraudulent collusion, it is conceivable that the manager and auditor could substantially tamper with a continuous audit system and circumvent its alarms and warnings. Indeed, CA systems may be more vulnerable to such interference than a standard audit, given $\mathrm{CA}^{\prime}$ 's greater reliance on automated procedures.

The main goal of the proposed BB log system is to cover this fundamental "Achilles' Heel" of the CA system, that the very people that it is meant to monitor can manipulate it. The log file takes advantage of the electronization of the firm to create revolutionary new audit methodologies, rather than simply using technology to automate existing audit methods. The log file also serves as a valuable source of institutional memory in the event of mandated auditor rotation. The value of the log file is greater in environments with weaker substitutes for ensuring auditor integrity, making it particularly well suited for a developing economy like China. While the high level of technical sophistication that it demands will restrict the use of the BB log file to the most advanced and internationally minded Chinese firms, logging will also serve to give these firms critical credibility on the world financial stage. 
The People's Republic of China is an emerging giant in the world economy, but as its government has clearly recognized, a prerequisite for reaching the next level of development are modern and rigorous systems of corporate governance and auditing. In much the same way as many developing economies were able to skip the intermediary step of landlines and leapfrog to cutting edge wireless telephony, so the PRC has the opening to put the lessons learnt from the recent US experiences into practice faster than other countries and thereby gain a true competitive advantage as a result. It is after all, reputed to be an old Chinese proverb that states, "In every crisis there is an opportunity" and it is an even happier set of circumstances if the opportunity arises from someone else's crisis.

\section{REFERENCES}

AICPA. (1997): "Report of the Special Committee on Assurance Services". http:/ /www.aicpa.org/assurance/scas/newsvs/reliab/index.htm.

ALLES, M.; KOGAN, A; VASARHELYI, M. (2002): "Feasibility and Economics of Continuous Assurance", Auditing: A Journal of Practice and Theory,21:1, pp.125-138.

ALLES, M.; KOGAN, A; VASARHELYI, M. (2003a): "Restoring Auditor Credibilty: Tertiary Monitoring and Logging of Continuous Auditing Systems", Unpublished working paper, Rutgers Business School.

ALLES, M.; KOGAN, A; VASARHELYI, M. (2003b): "Should Auditing be Completely Separated from Consulting in the Post-Enron Era?" Unpublished working paper, Rutgers Business School.

AMERICAN CHAMBER OF COMMERCE IN THE PEOPLE'S REPUBLIC OF CHINA. (2002): "Professional Services: Accounting Services", White paper: http://www.amcham-china.org.cn/publications/white/2002/en-26.htm.

BELL, T.; MARRS, F.; SOLOMON, I.; THOMAS, H. (1997): “Auditing Organizations Through A Strategic Lens: The KPMG Business Measurement Process", Montvale, NJ: KPMG Peat Marwick, LLP.

CHEUNG, S. (1999): "Corporate Governance in Hong Kong, China: Rising to the Challenge of Globalization". In Rising to the Challenge in Asia: A Study of Financial Markets, Asian Development Bank, 3, pp. 1-17. 
CICA/AICPA (1999): “Continuous Auditing. Research Report”, Toronto, Canada: The Canadian Institute of Chartered Accountants.

EUROPEAN CHAMBER OF COMMERCE IN CHINA (2001): Accounting, Auditing and Taxation Working Group Position Paper.

GEIGER, M.; RAGHUNANDAN, K. (2002): "Auditor Tenure and Audit Reporting Failures", Auditing: A Journal of Practice \& Theory, 21:1, pp. 67-78.

KOGAN, A.; SUDIT, E.; VASARHELYI, M. (1999): "Continuous Online Auditing: A Program of Research", Journal of Information Systems. 13:2, pp. 87103.

NARAYAN, F.; REID, B. (2000): "Financial Management and Governance Issues in the People's Republic of China", Asian Development Bank.

SLIVOTZKY, A.; MORRISON, D. (2000): "How Digital is Your Business?", Crown Business Publishers, New York.

VASARHELYI, M. (2002): "Concepts in Continuous Assurance". In Sutton, S. and V. Arnold, Monograph on Accounting Information Systems, American Accounting Association, Forthcoming.

VASARHELYI, M.; GREENSTEIN, M. (2002): “The Electronization of Business: Managing the Edge”, Unpublished manuscript, Rutgers Business School.

VOARINO, P.; VASARHELYI, M. (2002): “Continuous Performance and Control Monitoring at a Major Italian Bank", Unpublished working paper, Rutgers Business School.

WEBB, A. (2002): "Big Trouble in Big China", The Association of Chartered Certified Accountants, April 1. http://www.acca.co.uk/publications/ accountingandbusiness/405124. 